\title{
REFORMASI DAN PENDIDIKAN KRISTEN: MENELUSURI WARISAN REFORMASI DALAM PENDIDIKAN KRISTEN
}

\author{
Alfius Areng Mutak
}

\begin{abstract}
Abstraksi: Tujuan utama dari tulisan ini ialah untuk melihat relasi antara peringatan 500 tahun reformasi dengan pendidikan Kristen. Reformasi yang dilakukan oleh Martin Luther dengan menempelkan sembilan puluh lima dalil di pintu gereja di kota Wittenberg, Jerman sebagai protesnya terhadap teologi dan pengajaran gereja pada 31 Oktober 1715 telah memberikan dampak yang sangat besar dalam pendidikan Kristen.
\end{abstract}

Dampak-dampak itu dapat dilihat dari banyak kontribusi yang diberikan oleh gerakan reformasi bagi dunia pendidikan di seluruh dunia. Hal itu dapat dilihat dari munculnya tokoh-tokoh penting yang berjuang bagi pendidikan baik di Eropa, Amerika, dan Indonesia. Kenyataan ini tentu tidak mengherankan karena sejak semula perjuangan yang dilakukan oleh Martin Luther dan kawan-kawan adalah berjuang selain bagi iman dan teologi, ia juga berjuang dalam bidang pendidikan. Hal yang sama dilakukan oleh John Calvin yang dibuktikan dengan didirikannya Jenewa Academy sebagai tempat belajar.

Bukan hanya itu, beberapa pakar pendidikan seperti Yohanes Amos Comenius, Johann H. Pestalozzi, dan Robert Raikes telah memberikan kontribusi yang besar bagi pendidikan di Eropa. Hal yang sama juga terjadi di Amerika tiga tokoh gereja Reformed seperti Louis Berkhof, Cornelius Van Till, dan Nicholas P. Wolterstorff. Karena gereja-gereja garis utama di Indonesia berasal dari Calvinis, maka tidak bisa ditampik bahwa gerakan reformasi 
telah memberikan kontribusi yang besar bagi pendidikan Kristen di Indonesia.

Kata-kata Kunci: Pendidikan Kristen, Reformasi, Calvinisme

Abstract: The main purpose of this article is to look at the relationship between 500 years anniversary of reformation movement and Christian education. Reformation which was begin when Luther nailed 95 tesis in front of the church in Wittenberg, Jerman had a great impacts in Christian education.

The impacts can be seen on some great person who had paid attention on education in Europe and the United State, even in Indonesia. To name some of them such as John Calvin, Amos Comenius, Louis Berkhof, Van Till, N. Wolterstorff and many others. As a result there were many Christian institutions such as Christian schools and Christian higher education has been established by churches under Reformed church all over the world including Indonesia.

Keywords: Christian education, Reformation, Calvinism

\section{PENDAHULUAN}

Beberapa waktu yang lalu tepatnya pada pertengahan Juli 2017 penulis bertemu dengan salah seorang rekan dalam sebuah penugasan. Setelah saling memperkenalkan diri penulis baru tahu bahwa rekan ini berasal dari Perguruan Tinggi Kristen yang cukup dikenal di negeri ini. Pertemuan itu berlanjutkan dengan pembicaraan yang asyik mulai dari dunia akademis sampai pada dunia gereja dan pelayanan. Ketika berbicara tentang gereja dan pelayanan, rekan ini tiba-tiba mengarahkan pembicaraan pada peringatan 500 tahun Reformasi. Rekan ini menceritakan beberapa gereja dan lembaga pendidikan teologi mengagendakan berbagai 
acara mulai dari ibadah sampai pada seminar dan simposium teologi dalam rangka peringatan 500 tahun gerakan reformasi. Dari percakapan dengan rekan ini, penulis menangkap ada sebuah sinyal yang menunjukkan bahwa gerakan reformasi gereja yang dilakukan oleh para reformator 500 tahun yang lalu tersimpan dengan baik dalam benak sebagian anggota gereja untuk melihat apa kontribusi nyata dari gerakan reformasi itu dalam konteks kehidupan gereja masa kini.

Dalam artikel ini, penulis tidak akan membahas tentang sejarah serta dasar-dasar perjuangan reformasi 500 tahun yang lalu, tetapi artikel ini akan lebih fokus membahas tentang implikasi dari reformasi bagi perkembangan dan pembaharuan dalam dunia pendidikan Kristen. Sesuai dengan bidang yang digeluti oleh penulis, maka dalam tulisan ini penulis akan menyoroti kontribusi dari semangat dan gerakan reformasi bagi pelayanan gereja dan pendidikan Kristen di Indonesia. Penulis meyakini bahwa gerakan dan semangat reformasi telah memberikan kontribusi yang besar bagi gereja dan pelayanan pendidikan Kristen di Eropa, Amerika, dan Indonesia. Sedangkan yang dimaksudkan dengan pendidikan Kristen dalam tulisan ini ialah mencakup semua unsur pendidikan mulai dari pendidikan pelayanan gereja dari sekolah minggu sampai pada pendidikan Kristen di sekolah dan perguruan tinggi.

Karena semangat dari gerakan dan perjuangan reformasi sesuai dengan namanya telah menghasilkan pembaharuan, maka artikel ini mendasarkan pembahasan pada semangat dari teologi reformed yaitu "semper reformente, semper reformande, seculum verbum Dei" artinya selalu diperbaharui untuk memperbaharui, sesuai dengan Firman Tuhan. 


\section{Menelusuri Sejarah dan Kontribusi Gerakan Reformasi bagi Pendidikan Kristen}

Dalam sebuah acara di televisi swasta beberapa bulan yang lalu diadakan peringatan enam belas tahun reformasi mahasiswa Indonesia dalam rangka memperingati kasus berdarah yang dikenal dengan kasus Semanggi. Acara peringatan itu disertai dengan talk show yang menghadirkan orang tua dan para penggiat nasib orang hilang pada zaman Orde Baru dengan tema "To be True to History" (Jujur pada Sejarah). Dalam diskusi dan talk show itu para orang tua korban Semanggi dan para penggiat nasib orang hilang sekali lagi menyerukan kepada pemerintah Indonesia agar mengungkapkan apa sebenarnya yang terjadi dengan anak-anak mereka yang telah menjadi korban dari upaya protes mereka terhadap kebijakan pemerintah yang dianggap otoriter pada saat itu. Sejarah adalah sebuah peristiwa dari sebuah fakta yang sebenarnya. Tetapi dalam kenyataannya ada banyak fakta sejarah yang telah diputarbalikkan sehingga tidak sesuai dengan fakta sejarah yang sebenarnya. Itulah yang menjadi dasar dari tuntutan para orang tua korban kasus Semanggi agar fakta sejarah yang sebenarnya diungkapkan seperti apa adanya.

Berbicara tentang sejarah, tahun ini umat Kristiani khususnya gereja-gereja Kristen Protestan di seluruh dunia dibawa pada sebuah sejarah yang luar biasa besarnya bagi gereja dan kekristenan; sejarah itu adalah sejarah 500 tahun reformasi. Teristimewa tahun ini karena pada tanggal 31 Oktober 2017 ini tepat 500 tahun perjuangan yang dilakukan oleh Marthin Luther ketika ia mendeklarasikan imannya dengan menempelkan sembilan puluh lima dalil di tembok kota Wittenberg Jerman yang dikenal dengan hari Reformasi. ${ }^{1}$ Banyak gereja memandang bahwa ini

\footnotetext{
${ }^{1}$ Thomas Van den End, Harta Dalam Bejana: Sejarah Gereja Ringkas (Jakarta: BPKGunung Mulia, 1980), 161.
} 
adalah bagian penting dari sejarah gereja yang harus diperingati dengan berbagai cara mulai dari kegiatan yang berskala akademis seperti seminar dan diskusi-diskusi ilmiah sampai pada kegiatan dalam bentuk ibadah dan doa syukur.

\section{Gerakan Reformasi dan Kontribusinya bagi Pendidikan Kristen}

Ada banyak tokoh reformator yang terlibat dalam gerakan reformasi, sebut saja nama-nama besar seperti Philip Melancthon, Huldreich Zwingli, namun pengaruh reformasi pada pendidikan Kristen ditemukan dalam pemikiran dan visi dari dua tokoh besar yaitu Martin Luther dan John Calvin. ${ }^{2}$

Sebagai tokoh utama dalam pergerakan reformasi, Martin Luther memiliki andil yang sangat besar dalam sejarah gereja dan pendidikan Kristen. Perjuangan utama Luther ialah perjuangan doktrinal yang berusaha membangun teologi yang didasarkan atas penafsirannya terhadap Kitab Suci sebagai kebenaran Firman Tuhan dengan keyakinan yang kokoh bahwa manusia dibenarkan hanya karena imannya (sola fide), manusia diselamatkan karena anugerah semata (sola gracia), meyakini bahwa Kitab Suci adalah Firman Tuhan dan satu-satunya dasar dan ajaran yang benar (sola scriptura), keyakinan Kristus adalah anak Allah yang datang menyelamatkan umat manusia (sola christo), serta keyakinan yang mendalam bahwa segala kemuliaan itu adalah bagi Allah (soli deo gloria). Selain dari perjuangan doktrinal yang dibangun atas dasar penafsiran Kitab Suci yang benar, Martin Luther juga memberikan perhatian dan bahkan kontribusi yang besar bagi pendidikan Kristen. Hal ini terlihat dengan jelas ketika Luther mendesak para pemimpin di kota praja Jerman untuk mendirikan sekolah, dan

\footnotetext{
${ }^{2}$ Michael J. Anthony, Foundations of Ministry: An Introduction to Education for A New Generation (Malang: Penerbit Gandum Mas, 2012), 47.
} 
sebagian dari usaha itu berbuah, walaupun gagasan mulia itu tidak diwujudkan dalam sistem persekolahan yang mencakup kebutuhan semua anak Jerman. ${ }^{3}$

Michael. J. Anthony mengatakan bahwa pendekatan Luther terhadap penafsiran Kitab Suci dan kepeduliannya terhadap pendidikan kaum awam itulah yang mengokohkan kepeduliannya dalam sejarah pendidikan Kristen. ${ }^{4}$ Yang menjadi pertanyaan besar terhadap reformasi yang dilakukan oleh Luther adalah hak dari manusia untuk menilai praktek dan kebenaran yang dilakukan oleh gereja. Anthony lebih lanjut mengatakan upaya menerjemahkan Kitab Suci ke dalam bahasa awam yang dilakukan oleh Luther serta komitmennya terhadap kedaulatan Kitab Suci dilihat bukan hanya sekedar simbol dari reformasi; justru hal inilah yang menjadi pusat dari gerakan kembali kepada ajaran yang benar tentang Kitab Suci yang membedakan pendidikan Kristen dari semua sistem pengajaran lainnya. ${ }^{5}$

Salah satu gerakan pendidikan yang dilakukan oleh Luther ialah kembali kepada pendidikan Yahudi yang menempatkan rumah tangga sebagai pusat dari pendidikan iman. Selain itu keyakinan dan komitmen Luther terhadap sola scriptura menjadi dasar bagi pandangannya terhadap dunia dan kehidupan yang menjunjung tinggi Kitab Suci sesuai dengan posisinya yang benar dalam kehidupan dan proses pembelajaran; karena seluruh pemikiran, perspektif, dan perilaku manusia harus didasarkan pada Kitab Suci yang menjadi dasar dan norma hidup orang percaya.

\footnotetext{
${ }^{3}$ Robert, R. Boehlke. Sejarah Perkembangan Pikiran dan Praktek pendidikan Agama Kristen: Dari Yohanes Amos Comenius sampai Perkembangan PAK di Indonesia (Jakarta: BPK Gunung Mulia, 2003). 187.

${ }^{4}$ Michael J. Anthony. Foundations of Ministry: An Introduction to Education for A New Generation, 47.

${ }^{5}$ Ibid.
} 
John Calvin di Jenewa pun rajin dalam usaha mendirikan sekolah terutama Akademi Jenewa yang menjadi perguruan tinggi bagi bakal pemimpin Gereja Pro-Reformasi di seluruh Eropa. ${ }^{6}$ Menurut Aristarchus, Calvin sendiri juga seorang yang gemar belajar, dan tidak heran dalam teologi Calvin penekanan terhadap pentingnya khotbah dan pengajaran dalam teologi Calvin merupakan cerminan dari founding father ini. ${ }^{7}$ Calvin memegang prinsip bahwa iman yang benar adalah iman yang diikuti oleh daya pikir. Suatu dogma gereja hanya dapat dimengerti dan diterima bukan hanya bergantung pada pola pikir masyarakat yang menerima, tetapi juga bergantung pada daya pikir masyarakat yang menerimanya. Oleh sebab itu pendidikan sangat penting, dan Calvin sebagai tempat pembelajaran. ${ }^{8}$ Aristarchus lebih lanjut mengatakan bahwa pada zaman Calvin, pendidikan hanya terarah pada persiapan untuk para imam gereja Roma Katolik dan bukan pendidikan bagi masyarakat. Pendidikan bagi masyarakat tidak menjadi perhatian dan hal yang penting. ${ }^{9}$ Dalam pandangan Calvin, pemahaman atas pentingnya pendidikan berbeda dengan gereja zaman itu. Pengelolaan gereja ada di tangan penatua yang tentunya orang awam. Mereka harus membaca Alkitab, mereka harus tahu pengakuan imannya. Karena orang awam terlibat dalam pengelolaan gereja mereka harus belajar dasar-dasar bergereja. Maka, gereja Calvinis sangat menekankan pentingnya pendidikan. Seperti yang diungkapkan oleh Aristarchus sebagai berikut, "Sedemikian pentingnya pendidikan bagi gereja Calvinis sampaisampai John Knox, seorang Calvinis dari Scotland, mengaku

\footnotetext{
${ }^{6}$ Robert, R. Boehlke. Sejarah Perkembangan Pikiran dan Praktek pendidikan Agama Kristen, 187.

${ }^{7}$ Aristarchus Sukarto. "Pengaruh Calvinisme dalam Kehidupan Gereja dan Pendidikan di Indonesia" dalam Budiman Heriyanto \& Tim. Calvinis Actual (Jakarta: Komisi pengkajian Teologi Gereja Kristen Indonesia Sinode Wilayah Jawa Barat, 2010).

${ }^{8}$ Ibid., 221.

${ }^{9}$ Aristarchus Sukarto. "Pengaruh Calvinisme dalam Kehidupan Gereja dan Pendidikan di Indonesia", 221.
} 
bahwa pendidikan masyarakat merupakan benteng Protestantisme dan fondasi yang kuat bagi negara."10

Menurut Anthony, kontribusi lain dari Calvin terhadap pendidikan Kristen dapat dilihat dari upaya yang ia lakukan yaitu dengan menafsirkan dan menerapkan pengajaran Kitab Suci dan teologi yang berkaitan dengan kehidupan pribadi, gereja, dan bangsa. ${ }^{11}$ Karena itu, perspektif Calvinis terkait tanggung jawab negara, gereja, dan rumah tangga ada di bawah kekuasaan Tuhan, banyak mempengaruhi pemerintahan dan pendidikan di Eropa dan Amerika. Dalam bidang pendidikan, pendekatan Calvin tidak berbeda dengan Luther, yang menerima teori-teori dan metodologi pendidikan kontemporer. Namun demikian tujuan pendidikan harus tetap sesuai dengan tujuan dari pedoman perilaku dari Kitab Suci yaitu hal-hal yang menyangkut tentang karakter ilahi dan disiplin kehidupan Kristiani." Menurut Anthony, "Sesungguhnya, kefanatikan religius dari para reformis ini sering memimpin kepada inovasi pendidikan dan kreatifitas instruksional, tetapi tujuan akhir dari pedoman perilaku dari Kitab Suci dalam hal karakter ilahi dan disiplin kehidupan Kristen."13

Dalam sejarah pendidikan Kristen selain dari tokoh besar reformasi, ada nama-nama besar yang menjadi penerus dari perjuangan reformasi dan memberikan kontribusi besar dalam dunia pendidikan Kristen. Dalam artikel ini, penulis akan membahas tiga tokoh yaitu Yohanes Amos Comenius, Johann H. Pestalozzi, dan Robert Raikes.

\footnotetext{
${ }^{10}$ Aristarchus Sukarto. "Pengaruh Calvinisme dalam Kehidupan Gereja dan Pendidikan di Indonesia", 221.

${ }^{11}$ Michael J. Anthony, Foundations of Ministry: An Introduction to Education for A New Generation, 47.

${ }^{12}$ Ibid.

${ }^{13}$ Ibid., 48.
} 
Yohanes Amos Comenius (1592-1670) seorang pakar pendidikan dari Hongaria, menerima pendidikan teologi dari Lutheran di Universitas Hiedelberg. Ia menjadi seorang pendeta dan sekaligus pendidik Kristen yang hebat. Karya besar yang dihasilkannya ialah "Didactica Magna" yang membawa dirinya disebut sebagai Bapak Pendidikan Modern. Seperti dikatakan, Anthony Comenius sesungguhnya bukan mendahului zamannya, tetapi ia unggul dalam segala hal yang dilakukannya dalam masa sejarah pencerahan dan reformasi. ${ }^{14}$ Pada kenyataannya, teori Comenius menginspirasi munculnya pemikiran-pemikiran dan teori pendidikan baru.

Selain Comenius, Jacques Rousseau adalah satu filsuf dan pakar pendidikan yang sangat dikenal pada abad ketujuh belas. Lahir di tengah keluarga Calvinis di Perancis, ia dikenal sebagai seorang ahli pendidikan yang menghasilkan karya besar "Emile" sebuah teori pendidikan yang berkaitan dengan anak menyangkut tentang sifat, minat, dan kebutuhan anak. Teori ini berpengaruh pada dunia pendidikan abad kedua puluh.

Memasuki abad kesembilan belas, kontribusi pendidikan Kristen makin luas dan berkembang dengan munculnya nama besar seperti Johann H. Pestalozzi. Pestalozzi lahir dan dibesarkan di Zurich 1746. Perjuangannya untuk memperbaiki pendidikan di Swiss didasarkan atas keprihatinannya terhadap situasi sosial yang terjadi pada waktu itu yang menyebabkan banyak anak tidak dapat bersekolah. Pestalozzi sangat mempercayai kekuatan pendidikan untuk memerangi kemiskinan, ketidakpedulian, penyakit, rasa takut, dan kejahatan di antara orang-orang miskin. Hal itulah yang membawanya menjadi seorang ahli pendidikan yang menghasilkan teori pendidikan dari pengalaman di ruang kelas. Dasar dan praktek

\footnotetext{
${ }^{14}$ Michael J. Anthony, Foundations of Ministry: An Introduction to Education for A New Generation, 47.
} 
pendidikan yang dikembangkan oleh Pestalozzi telah mengilhami sejumlah pemikir masyarakat dan pejabat pemerintah untuk memprakasai rencana pendidikan untuk semua anak. ${ }^{15}$

Di tengah-tengah situasi yang sosial yang terjadi di Eropa khususnya di Inggris, pada abad kesembilan belas muncul nama Robert Raikes yang berjuang untuk memberikan pelajaran bagi anak-anak miskin dan papa, gerakan ini dikenal sebagai cikal bakal dari Sekolah Minggu. Gerakan ini mengisi kekosongan yang ditinggalkan oleh pendidikan umum. Kenneth O. Gangel dan Warren S. Benson sebagaimana dikutip oleh M. J. Anthony mengatakan, "Kepentingan pergerakan Sekolah Minggu sulit dilebih-lebihkan dalam sejarah pendidikan Kristen selama lebih dari 100 tahun. Sekolah Minggu hampir merupakan agen tunggal yang dominan, selain rumah, dalam pendidikan Kristen dari anakanak dan pemuda Protestan." 16

\section{Kontribusi Reformasi bagi Pendidikan Kristen di Amerika}

Dalam sejarah gereja Reformed modern ada tiga tokoh gereja Reformed Amerika yang disoroti untuk melihat konsep Reformed tentang pendidikan Kristen khususnya tentang sekolah-sekolah Kristen di Amerika. Ketiga tokoh tersebut adalah Loius Berkhof, Cornelius Van Till, dan Nicholas P. Wolterstorff. Loius Berkhof adalah guru besar dan President Calvin Theological Seminary yang dikenal dengan ketajaman yang menonjol dalam doktrin Kristen, sedangkan Cornelius van Till adalah seorang filsuf guru besar di Westminster Seminary, pada tahun 1942 ia adalah salah satu dari pendiri Philadelphia Montogomery Christian Academy yang sekarang memiliki lebih dari 700 murid di kampus-kampus di tiga

\footnotetext{
${ }^{15}$ Robert, R. Boehlke. Sejarah Perkembangan Pikiran dan Praktek pendidikan Agama Kristen, 263.

${ }^{16}$ Michael J. Anthony, Foundations of Ministry: An Introduction to Education for A New Generation, 49.
} 
komunitas di dekat Philadephia. ${ }^{17}$ Sementara Nicholas P. Wolterstorff adalah filsuf dan guru besar filsafat di Calvin Collage di Grand Rapids, Michigan, ia juga memegang jabatan di Free University of Amesterdam, pada saat yang bersamaan memegang jabatan penting pada jurusan filsafat di Divinity School Yale University, serta menjadi dosen tamu di Oxford University di Inggris. ${ }^{18}$

Sekolah-sekolah Kristen telah berdiri di Amerika Utara sejak tahun 1852. Banyak imigran Belanda dari gelombang imigrasi awal datang ke benua Amerika antara lain agar dapat dengan bebas mendidik anak-anak mereka di sekolah-sekolah Kristen dengan latar belakang teologi Reformed. Akibatnya didirikanlah sekolahsekolah kecil di manapun para imigran itu menetap. ${ }^{19}$ Perhatian Louis Berkhof terhadap pendidikan Kristen nampak jelas dalam sebuah seminar tentang pendidikan Kristen, ia mengingatkan tentang pentingnya sekolah-sekolah Reformed menjadi berkat bagi bangsa Amerika, dengan mengatakan demikian,

"Sejalan dengan bergantinya tahun dan bergantinya keadaan, tumbuh keyakinan dalam diri kita bahwa kita sangat-sangat memerlukan sekolah Kristen. Sekolah Kristen telah menjadi sumber anugerah yang tak ternilai bagi orang-orang Reformed di Belanda dan bagi negara di mana mereka menjadi pembentuk dasar yang sangat penting. Sekolah Kristen juga telah menjadi berkat bagi lingkungan Reformed di Amerika dan semoga anugerah Allah menolong kita untuk memberikan sesuatu yang berguna bagi kehidupan bangsa kita masing-masing.,"20

\footnotetext{
${ }^{17}$ Louis Berkhof; CorneliusVan Till, Dasar Pendidikan Kristen (Surabaya: Penerbit Momentum, 2008), x.

${ }^{18}$ Ibid.

${ }^{19}$ Wolterstorff, Nicholas.P. Mendidik untuk Kehidupan: Refleksi mengenaiPengajaran dan Pembelajaran Kristen, 3.

${ }^{20}$ Louis Berkhof; CorneliusVan Till, Dasar Pendidikan Kristen, 37.
} 
Dalam sejarah perkembangannya, sekolah-sekolah Kristen di Amerika pada awal tahun 1900 menghadapi dilema karena dianggap sebagai ancaman terhadap sekolah-sekolah umum. Louis Berkhof mengingatkan bahwa adalah tugas dan kewajiban gereja untuk terus mempertahankan dan mengembangkan sekolah-sekolah Kristen ini dengan baik sehingga dapat memberikan solusi terhadap masalah yang di hadapi.

Berkhof lebih lanjut menulis demikian,

"Pengalaman mengajarkan kita untuk menghargai sekolah ini. Orang Kristen lain telah sering mengucapkan selamat kepada kita atas kepemilikan sekolah ini, menggambarkan sekolah ini sebagai salah satu pilar utama gereja kita, dan menasehati kita untuk menjaga, melanjutkan, dan mengembangkannya. Walaupun banyak yang mengkritiknya sebagai sesuatu yang membahayakan kesatuan kehidupan bangsa, sekolah Kristen dengan pasti memberikan solusi terhadap masalah yang sekarang ini memberatkan sistem sekolah umum kita." ${ }^{21}$

Ketika memberikan dorongan dan semangat tentang pentingnya memajukan sekolah-sekolah Kristen di Amerika, Berkhof mengatakan, "Hal ini benar karena kita menganggap sekolah Kristen sebagai suatu berkat nyata yang sangat diharapkan. Kita menolak pendapat di sekitar kita yang mungkin mengendorkan semangat yang membahayakan sekolah-sekolah Kristen. Kita sangat berharap melihat sekolah Kristen berlanjut dan memberkati kita dengan buah-buahnya di masa depan seperti yang telah terjadi di masa lalu.",22

Selain mendapatkan kesempatan mengadakan seminarseminar tentang pendidikan Kristen, Louis Berkhof juga aktif menulis artikel. Salah satu esai Berkhof tentang pendidikan Kristen

\footnotetext{
${ }^{21}$ Louis Berkhof; CorneliusVan Till, Dasar Pendidikan Kristen, 38.

${ }^{22}$ Ibid.
} 
terkenal yang dimuat dalam buku Dasar Pendidikan Kristen tampak dari judulnya yaitu "Menjadi Reformed dalam Sikap Kita Terhadap Sekolah Kristen"23 yang oleh Johnson dikatakan telah "memberikan pengantar yang tidak ternilai kepada koleksi yang baru ini dan dengan jelas memberikan dasar pertimbangan, bahkan bersifat imperatif, bagi pendidikan Kristen. Lima esai yang lain semuanya mengaitkan pendidikan Kristen dengan doktrin-doktrin inti iman Kristen, dan semuanya tertata secara sistematis. ${ }^{24}$ Karena itu, Dennis E. Johnson lebih lanjut mengatakan, "Pembaca akan mengagumi kejelasan yang dibuat Berkhof mengenai relasi antara tugas pendidikan Kristen dan kebenaran-kebenaran utama dari iman Kristen." 25

Dalam mendampingi gereja melakukan tugas dan panggilan pendidikan Kristen, Louis Berkhof terus mengingatkan bahwa sekolah-sekolah Kristen yang ada dalam lingkungan gereja Reformed agar tetap Reformed,

"Apabila sekolah Kristen kita berlanjut di masa depan, sangatlah penting bagi kita untuk benar-benar bersikap Reformed terhadap sekolah tersebut. Maksudnya ialah kita harus memiliki sikap pemahaman yang kokoh tentang prinsip-prinsip utama yang merupakan dasar dari sekolah kita. Ini berarti kita harus yakin akan pentingnya sekolah Kristen bagi anak-anak kita. Ini berarti kita tidaklah setengah hati dalam berdoa, memberi, dan bekerja untuk pemeliharaan dan pengembangan sekolah tersebut. Ini juga berarti kita harus meyakinkan generasi mendatang tentang kebutuhan mutlak akan sekolah Kristen kita, dan harus mendorong mereka untuk berkorban dan bekerja untuk melanjutkan keberadaannya." 26

\footnotetext{
${ }^{23}$ Louis Berkhof; CorneliusVan Till, Dasar Pendidikan Kristen, xii.

${ }^{24}$ Ibid.

${ }^{25}$ Ibid.

${ }^{26}$ Ibid., 38.
} 
Komitmen dan kontribusi Cornelius Van Till dalam pendidikan tak dapat disangsikan lagi. Hal itu dibuktikan pada tahun 1942 ia ikut mendirikan Philadelphia Montogomery Christian Academy yang sekarang memiliki lebih dari 700 murid di kampus-kampus di tiga komunitas di dekat Philadephia. Waktu yang diberikan (1930-1933) menunjukkan komitmen Van Till terhadap dunia pendidikan Kristen. ${ }^{27}$ Kontribusi lain yang diberikan Van Till dalam pendidikan Kristen ialah ketika ia menulis beberapa esai yang sangat penting terkait dengan masalahmasalah filosofis yang mendasar dan terkait dengan kehidupan sekolah-sekolah Kristen sehari-hari. ${ }^{28}$ Salah satu esai yang menonjol tentang pendidikan Kristen yang ditulis oleh Cornelius Van Till dengan judul Kehidupan yang Utuh. Dalam esai itu, Van Till secara dramatis mengkritik kesia-siaan usaha manusia untuk memformulasikan tujuan akhir dari pendidikan dan menegaskan puncak dari pengudusan dan sukacita yang merupakan pengharapan Kristen. $^{29}$

Cornelius Van Till juga diundang dalam seminar yang dihadiri oleh para praktisi pendidikan Kristen dengan judul Kepentingan dan Kekhususan Pendidikan Kristen Dalam Perspektif Reformed. ${ }^{30}$ Selain itu, dalam tugas utamanya sebagai guru besar di Westminster Seminary ia secara berkala mengunjungi beberapa daerah seperti Michigan, Illinois, Iowa untuk memberikan dorongan dan tantangan kepada guru-guru di sekolah Kristen. ${ }^{31}$ Pada bagian lain dalam upayanya mencoba memberikan solusi terhadap polemik yang dihadapi oleh dunia pendidikan di Amerika, Cornelius Van Till dan Louis Berkhof menunjukkan keterlibatan

\footnotetext{
${ }^{27}$ Louis Berkhof; CorneliusVan Till, Dasar Pendidikan Kristen, x.

${ }^{28}$ Ibid., xi.

${ }^{29}$ Ibid., xii.

${ }^{30}$ Ibid., 1 .

${ }^{31}$ Ibid., xi.
} 
mereka dengan berusaha menjelaskan pertimbangan yang lebih mendalam bagi sekolah Kristen.

Terkait dengan kontribusi Gereja Refomed Amerika terhadap Pendidikan Kristen, Gloria Goris Stronks dan Clarence W. Joldersma dalam prakata buku Nicholas. P. Wolterstorff dengan judul Mendidik untuk Kehidupan mengatakan, "Tidak banyak orang yang telah begitu mempengaruhi perkembangan sekolahsekolah Kristen di dalam tradisi Reformed di Amerika Utara dan bahkan di seluruh dunia seperti filsuf Nicholas Wolterstorff.",32 Gloria Goris juga mengatakan perhatian Wolterstotff dalam dunia pendidikan Kristen adalah luar biasa karena "sepanjang kariernya yang mengagumkan, Wolterstorff selalu bersedia meluangkan waktu untuk memberikan petunjuk-petunjuk yang penting bagi sekolah-sekolah Kristen. Pekerjaannya dalam bidang itu sangat dihargai oleh guru-guru dan para pengelola sekolah."33

Dalam bukunya Mendidik untuk Kehidupan, Wolterstorff memberikan gambaran tentang keberatan-keberatan yang dihadapi oleh sekolah Kristen dalam dunia yang sedang berubah. Ia mendeskripsikan asal usul dari sekolah-sekolah Kristen Reformed serta menjelaskan tiga titik kritis yang dihadapi sekolah-sekolah ini selama masa tujuh puluh lima tahun dari eksistensinya. Wolterstortff merangkum tradisi Calvinis dan menyatakan bahwa sekolah-sekolah Kristen bertugas menerima visi itu dan mewujudkannya secara konkret. $^{34}$ Wolterstorff mengatakan, "Kehidupan yang untuknya kita mendidik adalah kehidupan yang dipenuhi oleh rasa syukur dalam tanggung jawab penyembahan dan penghargaan." Dan menyangkut tentang kontribusi gereja-gereja Calvinis terhadap pendidikan di Amerika, Woltersorff menulis,

\footnotetext{
${ }^{32}$ Nicholas, P. Wolterstorff, Mendidik untuk Kehidupan: Refleksi mengenai Pengajaran dan Pembelajaran Kristen, ix.

${ }^{33}$ Ibid.

${ }^{34}$ Ibid., Xv.
} 
"Saya sering bertanya-tanya apa yang akan terjadi seandainya tidak pernah ada gerakan sekolah swasta Calvinis di benua Amerika utara hari ini?",35

Perhatian Wolterstorff terhadap pendidikan Kristen juga dapat dilihat dari banyaknya buku dan artikel yang ditulis serta kesempatan-kesempatan mendapatkan undangan dari berbagai lembaga pendidikan Kristen untuk menyampaikan seminar dan ceramah. Pada tahun 1966, Wolterstorff pernah diundang untuk menyampaikan ceramah tentang topik kurikulum pada pertemuan tahunan NUCS dari para kepala sekolah dan dewan pengurus sekolah. ${ }^{36}$ Dalam ceramah itu, Wolterstortff mengemukakan bahwa orang-orang Kristen harus berupaya memperlengkapi murid-murid agar dapat mengarungi kehidupan Kristen. Kemudian ia memaparkan berbagai dimensi kehidupan Kristen yang amat relevan dalam mengambil keputusan yang berhubungan dengan pendidikan. Menurut Wolterstortff, karakteristik pendidikan sekolah swasta Calvinis yang sejati ialah ketegasan bahwa pendidikan seperti semua hal lainnya harus berada di bawah Ketuhanan Yesus Kristus."37 Dan tugas pendidikan Kristen mempunyai dua dimensi yaitu tugas untuk perkembangan, dan tugas untuk penyembuhan. Kita membutuhkan keduanya dan tugas penyembuhan harus digerakkan oleh ratapan sesungguhnya.

Pada tahun 1980, Wolterstorff menerbitkan buku berjudul Education for Responsibble Action. Dalam bukunya ini, Wolterstortff menekankan interaksi dari tiga strategi yang harus dipelajari oleh murid di sekolah yaitu berdisiplin tinggi, mampu menjadi teladan, dan mampu berargumentasi. ${ }^{38}$ Tiga tahun

\footnotetext{
${ }^{35}$ Nicholas, P. Wolterstorff, Mendidik untuk Kehidupan: Refleksi mengenai Pengajaran dan Pembelajaran Kristen, 118.

${ }^{36}$ Ibid., 4.

${ }^{37}$ Ibid., 191.

${ }^{38}$ Ibid., 376.
} 
kemudian ia bersama Hart, H. J.Van D Hoeven sebagai editor dari buku Rationality in the Calvinian Tradition, Notre Dame: University of Notre Dame Press, 1983. Setelah itu ia bersama Plantinga A. sebagai editor dari buku Faith and Rationality: Reason and Believe in God, Norte Dame: University of Norte Dame Press, 1983. Selain dari menerbitkan buku, Wolterstorff juga menulis beberapa artikel di antaranya dalam Lutheran Education 134, No 3 (1999) 129-40 dengan judul "Christian Higher Eduation in Reformed Perspektif." Dalam ceramahnya di Calvin College tahun 1999, Wolterstorff menyatakan bahwa, "Sasaran pendidikan adalah tindakan yang bertanggung jawab dan bahwa murid harus belajar untuk hidup dengan rasa syukur."39

\section{Kontribusi Reformasi dalam Pendidikan Kristen di Indonesia}

Aristarchus dalam tulisannya tentang pengaruh Calvinisme dalam Kehidupan Gereja dan Pendidikan di Indonesia mengatakan bahwa legasi pandangan teologis Calvinis berpengaruh terhadap kehidupan gereja-gereja di Indonesia. ${ }^{40}$ Praktek kehidupan gereja Calvinis di Indonesia juga dapat dikatakan mengikuti praktik kehidupan gereja Calvinis pembawanya termasuk di dalamnya perhatian terhadap dunia pendidikan. Sejak tahun 1906, gereja Calvinis di Indonesia mulai mendidik untuk tenaga pelayan gerejawi dan sekolah-sekolah dasar. Pada tahun 1937 ada seratus lima puluh sembilan sekolah dasar dan lima puluh sekolah menengah yang dikelola oleh GKN; hal ini menunjukkan betapa pentingnya perhatian gereja Calvinis terhadap pendidikan. Aristarchus lebih lanjut mengatakan bahwa memang secara tradisional gereja-gereja Presbyterian maupun Reformed sangat menekankan standar yang tinggi untuk pendidikan dan pelayanan

\footnotetext{
${ }^{39}$ Ibid Nicholas, P. Wolterstorff, Mendidik untuk Kehidupan: Refleksi mengenai Pengajaran dan Pembelajaran Kristen, 365.

${ }^{40}$ Aristarchus Sukarto, "Pengaruh Calvinisme dalam Kehidupan Gereja dan Pendidikan di Indonesia", 218.
} 
gerejanya. Karena keyakinan ini, dapat dikatakan kemana saja orang-orang Calvinis bergerak, maka mereka akan membawa atau mendirikan sekolah-sekolah bukan hanya mendirikan gereja.

Menurut Aristarchus, praktek kehidupan yang menunjukkan eratnya hubungan antara Calvinisme dan pendidikan dapat kita lihat dalam sejarah perguruan-perguruan tinggi seperti Universitas Kristen Satya Wacana (UKSW) yang didirikan tahun $1956 .^{41}$ Sekolah Tinggi Teologi Duta Wacana yang sekarang menjadi Universitas Duta Wacana di Yogyakarta, Sekolah Tinggi Teologi Jakarta dan beberapa sekolah Kristen seperti Sekolah Kristen Penabur milik Gereja Kristen Indonesia Jawa Barat, dan masih banyak lagi sekolah-sekolah Kristen dan perguruan tinggi Kristen seperti Universitas Petra Surabaya.

Dalam kaitannya dengan kontribusi gereja-gereja Calvin dalam pendidikan nasional, Ellisabeth Haskini menulis, "Betapa sekolah-sekolah Kristen di tanah air ikut mengambil peran yang tidak sedikit. Kenyataan tersebut menegaskan bahwa pemikiran Calvin yang mengalir dalam gereja Calvinis mengakui bahwa pendidikan masyarakat amat penting bukan saja sebagai benteng Protestantisme tetapi juga sebagai fondasi kuat bagi negara."42

Mengapa gereja Calvinis menaruh perhatian yang dalam bagi pendidikan Kristen? Hal ini dapat dipahami karena gereja Calvinis mewariskannya dari pandangan Agustinus yang menekankan perlunya seseorang mengembangkan akal pikiran agar dapat mengenal jalan Tuhan dan diwujudkan dalam semangat Calvin yang mempromosikan pendirian-pendirian sekolah, karena gereja

${ }^{41}$ Aristarchus Sukarto, "Pengaruh Calvinisme dalam Kehidupan Gereja dan Pendidikan di Indonesia", 122.

${ }^{42}$ Ellisabeth Haskini, "Tanggapan Terhadap Makalah Aristarchus Sukarto dengan Judul Pengaruh Calvinisme dalam Kehidupan Gereja dan Pendidikan Kristen di Indonesia." Dalam Budinam Heryanto, dan Tim. Calvinis Actual (Jakarta: Komisi Pengkajian Teologi Gereja Kristen Indonesia Sinode Wilayah Jawa Barat, 2010). 228. 
tidak akan dapat bertahan tanpa adanya pendidikan dan sebuah masyarakat akan punah tanpa mempertahankan pendidikan. ${ }^{43}$ Karena itu, Aristarchus menyerukan, "Bagi gereja-gereja Calvinis, secara teologis dan sosial, pendidikan itu adalah sebuah panggilan. Seharusnya antusiasme gereja maupun masyarakat gereja yang Calvinis, semangat pendidikan itu harus tetap ada." "44 Ellisabeth lebih lanjut mengatakan corak Calvinis dalam ketertiban dan keteraturan mewarnai banyak sekolah Kristen di tanah air. Keterlibatan dan keteraturan dimengerti sebagai sebuah tindakan disiplin sekolah yang dianggap oleh masyarakat sebagai yang amat positif. Sekolah juga sering diidentikkan sebagai sarana belajar tentang moral dan etika yang dianggap baik oleh masyarakat. ${ }^{45}$

Namun di tengah perkembangan dan kemajuan yang dicapai oleh pendidikan Kristen di negeri ini serta dengan berjalannya waktu, kemajuan dan perkembangan sekolah-sekolah Kristen mengalami stagnasi bahkan kemunduran. Dari sekian banyak penyebab, salah satunya ialah karena kurangnya dukungan dari gereja-gereja terhadap sekolah-sekolah Kristen. ${ }^{46}$ Kiranya melalui peringatan 500 tahun reformasi, gereja-gereja Calvinis diingatan kembali misi dan perjuangan para tokoh reformator. Seperti yang diungkapkan oleh Elllisabeth Haskini bahwa pemikiran Calvin yang utama yaitu melakukan pembaharuan, maka sudah waktunya dunia pendidikan Kristen berbenah diri untuk melakukan pembaharuan baik secara struktural maupun secara praktis."

\footnotetext{
${ }^{43}$ Ellisabeth Haskini, “Tanggapan Terhadap Makalah Aristarchus Sukarto dengan Judul Pengaruh Calvinisme dalam Kehidupan Gereja dan Pendidikan Kristen di Indonesia." 228

${ }^{44}$ Ibid.

${ }^{45}$ Ibid.

${ }^{46}$ Ibid.

${ }^{47}$ Ibid., 231.
} 


\section{SIMPULAN}

Peringatan 500 tahun reformasi seharusnya menjadi sebuah fenomenal, karena momen itu adalah momen memperingati sebuah sejarah besar yang telah menjadi legasi dan tonggak sejarah yang luar biasa. Pujian dan syukur tentu perlu dinaikkan kepada Kristus yang adalah kepala gereja yang menganugerahkan momen luar biasa itu. Tentu hal ini tidak cukup, sebagai gereja yang hari ini telah mendapatkan kontribusi yang besar seharusnya bisa berbuat lebih dari itu.

Sejarah telah membuktikan bahwa reformasi 500 tahun yang lalu telah memberikan kontribusi yang besar bagi pendidikan dan pelayanan gereja khususnya pendidikan Kristen. Tidak bisa ditampikkan bahwa lembaga-lembaga pendidikan dasar maupun pendidikan tinggi yang cukup dikenal di Amerika sebut saja Harvard, Princeton, dan banyak lainnya lagi adalah hasil atau buah dari pendidikan Kristen. Di Indonesia kontribusi reformasi ke dalam pendidikan Kristen juga dapat dilihat dari beberapa lembaga pendidikan mulai dari tingkat dsar sampai pada perguruan tinggi sebut saja Sekolah Penabur dan beberapa universitas Kristen seperti Universitas Kristen Satya Wacana.

Tantangan yang dihadapi oleh pendidikan Kristen di negeri ini ialah bagaimana membangun dan mengembangkan lembagalembaga pendidikan ini agar dapat terus diperbaharui serta mampu bersaing di tengah-tengah persaingan global, sesuai dengan semangat dari gereja Reformed: "Semper reformente, semper reformande, seculum verbum Dei" artinya selalu diperbaharui untuk memperbaharui sesuai dengan Firman Tuhan. 


\section{DAFTAR PUSTAKA}

Anthony, J. Michael, Foundations of Ministry: An Introduction to Education for A New Generation (Terj) (Malang: Penerbit Gandum Mas, 2012).

Berkhof, Louis; CorneliusVan Til, Dasar Pendidikan Kristen (Surabaya: Penerbit Momentum, 2008).

Boehlke, R. Robert. Sejarah Perkembangan Pikiran dan Praktek Pendidikan Agama Kristen: Dari Yohanes Amos Comenius sampai Perkembangan PAK di Indonesia (Jakarta: BPK Gunung Mulia, 2003).

Haskini, Ellisabeth, "Tanggapan Terhadap Makalah Aristarchus Sukarto Dengan Judul Pengaruh Calvinisme Dalam Kehidupan Gereja dan Pendidikan Kristen di Indonesia." dalam Budinam Heryanto, dan Tim. Calvinis Actual (Jakarta: Komisi Pengkajian Teologi Gereja Kristen Indonesia Sinode Wilayah Jawa Barat, 2010).

Sukarto, Aristarchus, "Pengaruh Calvinisme dalam Kehidupan Gereja dan Pendidikan di Indonesia" dalam Budiman Heriyanto \& Tim. Calvinis Actual (Jakarta: Komisi pengkajian Teologi Gereja Kristen Indonesia Sinode Wilayah Jawa Barat, 2010).

Van den End, Th. Harta Dalam Bejana: Sejarah Gereja Ringkas (Jakarta: Penerbit BPKGunung Mulia, 1979).

Wolterstorff, Nicholas. P. Mendidik untuk Kehidupan: Refleksi Mengenai Pengajaran dan Pembelajaran Kristen (terj. Lana Asali, Surabaya: Penerbit Momentum, 2007). 